\title{
DYNAMIC AMPACITY RATING OF CONDUCTOR BARS IN HIGHLY LOADED SUBSTATIONS
}

\author{
Michael SCHMALE ${ }^{1}$ \\ TenneT TSO GmbH - Germany
}

\author{
Ralf PUFFER \\ RWTH Aachen University - Germany \\ puffer@ifht.rwth-aachen.de
}

\author{
Matthias HEIDEMANN \\ RWTH Aachen University - Germany \\ matthias.heidemann@rwth-aachen.de
}

\section{INTRODUCTION}

The growing demand for energy transmission capacity in the grid leads to an increased need of ampacity not only of overhead lines but also within substations. Retrofitting of bus bars and conductor bars in general often means rebuilding major parts of a substation. Hence the possibility of using a dynamic ampacity rating for conductor bars in highly loaded substation bays is investigated.

\section{AMPACITY OF CONDUCTOR BARS}

In German standards such as DIN 43670 and DIN 43671 the ampacity of outdoor conductor bars is given for summer ambient conditions only [1] [2]. An algorithm within the standards for calculating a weather dependent dynamic ampacity is missing. A physical model to calculate the ampacity of conductor bars is given in IEEE standard 605 [3]. It is based on solving the heat balance of heat input and output for a conductor bar. A standard method for calculating the ampacity of bare (stranded) overhead conductors is given in Cigré TB 207 [4]. This physical model is used to calculate the ampacity of conductor bars with circular ring cross sections.

The ampacity of conductor bars with a circular ring cross section is calculated using a heat balance, where four inputs are considered. These inputs are, firstly, the Joule heating $\left(\mathrm{P}_{\mathrm{J}}\right)$. Due to the resistance of the material and the current flowing through the conductor its temperature rises. Since the resistance of the conductor depends on its temperature $T_{\text {cond }}$, it is necessary to calculate the Joule heating with a pre-determined temperature and redo the calculation if the determined temperature has changed. The Joule heating may be calculated using equation (1), where $R_{\text {cond }}$ is the temperature dependent resistance and $I$ is the current flowing through the conductor bar.

$$
P_{J}=R_{\text {cond }}\left(T_{\text {cond }}\right) \cdot I^{2} \quad \text { eq. (1) }
$$

Secondly the global radiation $\left(\mathrm{P}_{\mathrm{S}}\right)$ is taken into account, which leads to an increase of the conductor's temperature. The global radiation may be calculated using equation (2), where $\alpha$ is the absorption coefficient, $A_{A}$ the surface area on which sunrays are absorbed and $W$ is the surface-density of the global radiation.

$$
P_{S}=\alpha \cdot A_{A} \cdot W
$$

Thirdly the temperature loss due to radiated power may be calculated using equation (3). In this equation $\varepsilon$ is the emission coefficient, $\sigma$ is the Stefan-Boltzmann constant, $A$ is the conductor's surface area and $T_{W}$ is a weighted temperature difference between the conductor's temperature and the ambient temperature [8].

$$
P_{R}=\varepsilon \cdot \sigma \cdot A \cdot T_{W}
$$

Finally, the temperature loss due to convective cooling is considered. These losses may be calculated using equation (4), where $h$ is the convective heat-transfer coefficient and $T_{A}$ is the ambient temperature.

$$
P_{C}=h \cdot A \cdot\left(T_{A}-T_{\text {cond }}\right)
$$

These four inputs are put into equation (5). Since three of the four inputs depend on the conductor's temperature the equation cannot be solved analytically for every variable. Hence an iterative algorithm is used to balance the equation. Using such algorithm, every quantity soughed can be determined.

$$
P_{J}+P_{S}=P_{R}+P_{C}
$$

The material's properties, the current load, the ambient temperature, the materials temperature and the wind speed and direction significantly influence the four inputs of the heat balance.

The suggested calculation of the four inputs is based on the model presented in Cigré TB 207 [4]. However, the calculation method was adjusted in some details regarding the differences between stranded overhead conductors and conductor bars. Firstly while calculating the Joule heating the correction factor $k_{\mathrm{j}}$ considering the skin effect is neglected, since the skin effect is insignificant for tube type conductor bars used in substations. Secondly the Reynolds number and the Nusselt number are calculated according to the Webs model [8]. Both quantities are determined while calculating the heat-transfer coefficient $h$. Finally the radiated power is calculated using the Webs model, too.

Using this model calculations prove the potential of dynamic ampacity rating for application in transmission and

\footnotetext{
${ }^{1}$ Dr. Michael Schmale our dear friend and co-author has passed away totally unexpected in November 2012. He has spend great effort in preparing the concept of dynamic ampacity rating and projecting the measurement system presented in this paper.
} 
distribution systems. Figure 1 shows that a decrease in ambient temperature at a wind speed of $0.6 \mathrm{~m} / \mathrm{s}$ leads to an ampacity increase of $1.5 \%$ per K. At a wind speed of $1 \mathrm{~m} / \mathrm{s}$ the ampacity increases about $1.7 \%$ per $\mathrm{K}$ decrease in ambient temperature. This demonstrates that the ampacity of a conductor bar may be increased significantly using current ambient weather data, compared to the values used for static summer ratings. At the same time it motivates the application of dynamic ampacity rating and the necessary investigations.

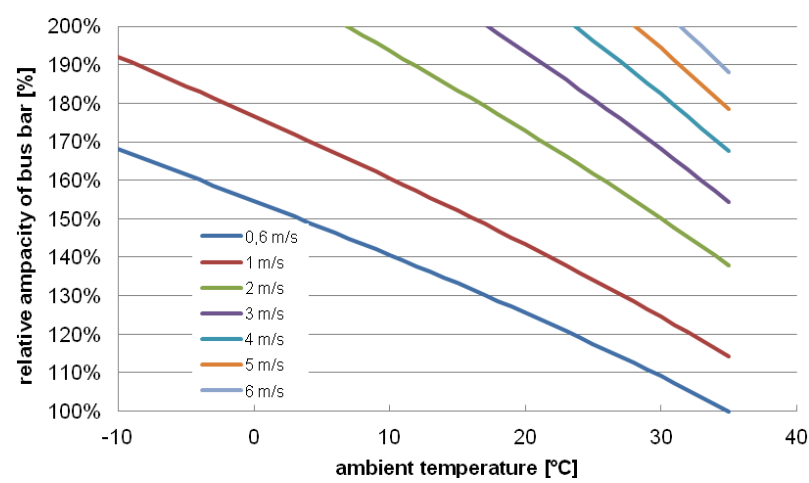

Figure 1: Ampacity of an Al 64/741 conductor bar depending on ambient temperature and wind speed

\section{CONCEPT OF INVESTIGATION}

The main aim of the investigation is to verify the dynamic ampacity approach for summer ratings as well as for ratings based on weather data.

To verify static summer ratings given in [1] and [2] the suggested model is used to calculate the ampacity of conductor bars for summer ambient conditions. The results are compared and this comparison should verify the model.

To determine the dynamic ambient based ampacity the approach for overhead lines given in [5] and [6] is used.

To verify the reliability of dynamic ampacity rating the following approach is used. Time resolved conductor bar temperature is calculated from the data used to determine the ampacity (ambient temperature, wind speed, solar radiation and conductor bar type, measured values of the line current). The calculated values of the conductor temperature are verified using measured values of the conductor temperature. The physical model to calculate the dynamic ampacity rating is assumed to be reliable if measured and calculated values are in good accordance.

To achieve the necessary ambient weather data and conductor bar's temperature appropriate measurement equipment is being installed on a highly loaded conductor bar in the Redwitz substation in Germany.

\section{COMPARISON OF CALCULATED AMPACITY AND NORMED VALUES FOR SUMMER ABMIENT CONDITIONS}

Since the normed values from [1] and [2] are given for summer ambient conditions, the weather conditions were set to $35^{\circ} \mathrm{C}$ ambient temperature, $0.6 \mathrm{~m} / \mathrm{s}$ wind speed vertical to the conductor bar and $1,000 \mathrm{~W} / \mathrm{m}^{2}$ global radiation. The conductor bar is assumed to be uncoated and outdoor installed (open air). Furthermore it is assumed that the conductor bar has already some degree of oxidation (emission ratio 0.5 ). The result of the comparison between calculated and standard values is given in table 1 . The relative difference is calculated with respect to the ampacity given in the standard.

\begin{tabular}{|c|c|c|c|c|c|}
\hline diameter & $\begin{array}{l}\text { cross } \\
\text { section }\end{array}$ & ampacity & difference & & \\
\hline $\begin{array}{c}\text { conduc-tor } \\
\text { bar [mm] }\end{array}$ & $\mathrm{Al}\left[\mathrm{mm}^{2}\right]$ & $\begin{array}{c}\text { standard } \\
{[\mathrm{A}]}\end{array}$ & $\begin{array}{c}\text { calculated } \\
{[\mathrm{A}]}\end{array}$ & $\begin{array}{c}\text { abso- } \\
\text { lute } \\
{[\mathrm{A}]}\end{array}$ & $\begin{array}{l}\text { rela- } \\
\text { tive }\end{array}$ \\
\hline 20 & 264 & 540 & 528 & -12 & $-2.2 \%$ \\
\hline 32 & 352 & 708 & 683 & -25 & $-3.5 \%$ \\
\hline 50 & 829 & 1,230 & 1,211 & -19 & $-1.5 \%$ \\
\hline 63 & 741 & 1,240 & 1,236 & -4 & $-0.3 \%$ \\
\hline 80 & 955 & 1,510 & 1,518 & 8 & $0.5 \%$ \\
\hline 100 & 1,490 & 2,020 & 2,043 & 23 & $1.1 \%$ \\
\hline 120 & 1,810 & 2,340 & 2,393 & 53 & $2.3 \%$ \\
\hline 160 & 1,960 & 2,710 & 2,745 & 35 & $1.3 \%$ \\
\hline 200 & 3,660 & 4,000 & 4,048 & 48 & $1.2 \%$ \\
\hline
\end{tabular}

Table 1: Aluminum conductor bars ampacity comparison (standard and calculated values)

Ampacities given in the standard do not differ more than $4 \%$ from the calculated ones. The reason for these deviations is not yet fully understood since the model used to calculate the ampacity in the standards is not known anymore. Thus an update of the German standards will be subject of further work. Nevertheless the accordance of the data is acceptable for practical applications.

\section{MEASURING CONDUCTOR BAR TEMPE- RATURES AND AMBIENT CONDITIONS}

Since calculated and measured conductor bar temperatures have to be compared, measurement data of conductor temperature, wind speed, global radiation and current is necessary. To measure the conductor bar temperature sensors have been installed on conductor bars within the switch bay of an incoming circuit.

Close to the conductor bar ambient temperature, wind speed and global radiation are measured using a weather station (see figure 2).

The current is measured using the standard current transformer within the substation bay of the incoming circuit. 


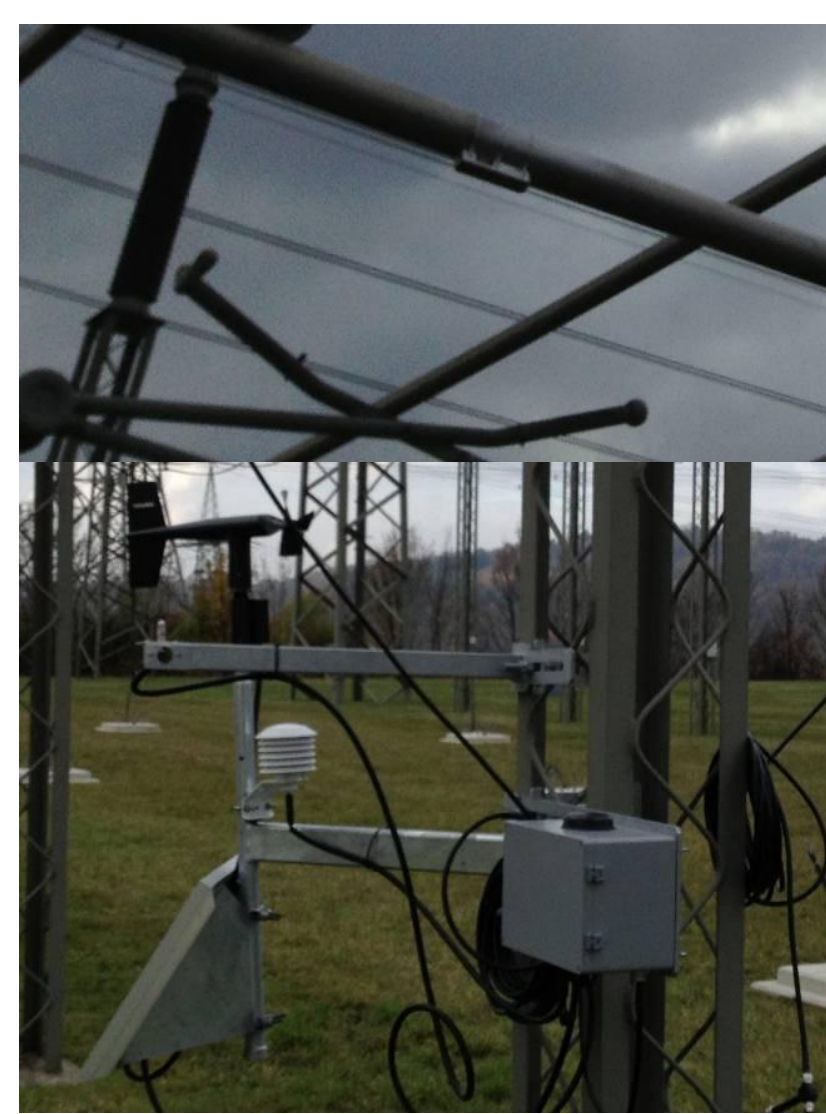

Figure 2: Temperature sensor on conductor bar (above) and sensors for weather data (below)

\section{COMPARISON OF MEASURED AND CALCU- LATED CONDUCTOR BAR TEMPERATURES}

Conductor temperature, ambient weather data and current has been recorded and evaluated for a period of two month in the winter season of 2012. Additionally the conductor temperature is calculated using the above given model. The ambient weather data and the measured current are used as input data for the calculation. In order to evaluate the accuracy of the model the calculated conductor temperature in compared to the measured conductor temperature. The difference between both values indicates the accuracy of the model. To clearly illustrate the trend within the results the difference between calculated and measured conductor temperatures is given as a frequency distribution. The advantage of a frequency distribution is the independence of the illustration from the time line of the measurements. Figure 3 shows the frequency distribution of the difference between calculated and measured conductor bar temperatures.

For $90 \%$ of the measurements the difference between measurement and calculation is within $+/-3^{\circ} \mathrm{C}$. Although this difference is acceptable for practical use of dynamic ampacity rating the reasons for these deviations will be investigated in future works. Furthermore the measurements will be extended to a period of at least one year to cover different ambient weather situations as well as current loads.

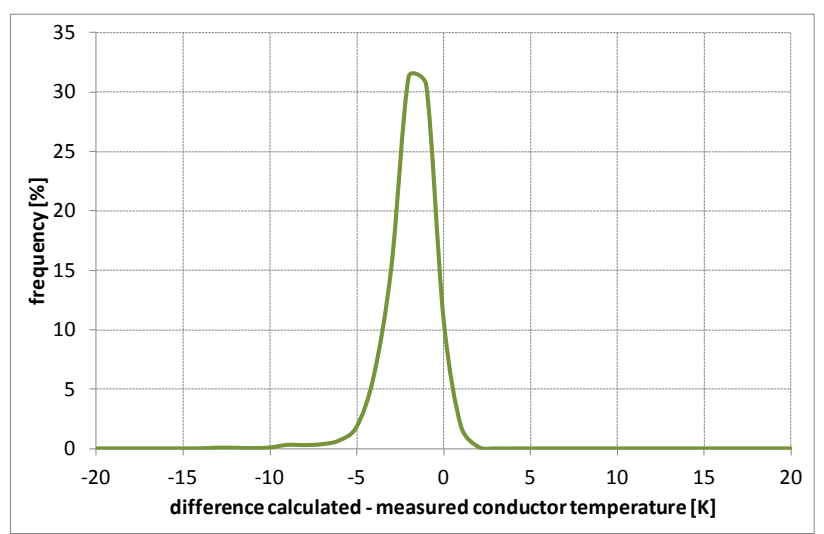

Figure 3: Frequency distribution of difference between calculated and measured temperatures of a $380 \mathrm{kV}$ conductor bar

Though current loads up to $90 \%$ of the conductor bar's current rating have been reached, maximum conductor temperatures were in the range of $25^{\circ} \mathrm{C}$. Since the rated maximum conductor temperature is $65^{\circ} \mathrm{C}$ the measured temperatures indicate that there is no risk in exceeding the temperature limit under those winter ambient conditions. During summer ambient conditions and high current loads on the conductor bar the conductor temperature is likely to come close to the rated temperature of $65^{\circ} \mathrm{C}$. In this summer situation an overestimation of the calculated ampacity might result in exceeding the rated conductor temperature. Since this should be avoided the model for calculating the ampacity should be adapted in further investigations. The aim is to adapt the model on a physical basis. The difference between calculated and measured conductor bar temperatures should be zero or some degrees above zero. The peak in figure 3 should move to positive values.

\section{AMPACITY USING DYNAMIC RATING}

The dynamic ampacity of a conductor bar depending on ambient temperature and wind speed has been shown in figure 1 . In this section the measured weather data is used to calculate the dynamic ampacity rating of the installed conductor bar. Figure 4 shows the values of the dynamic ampacity and the current load relative to the static rating of the conductor bar. The static rating is normalised to $100 \%$. Since to date the measurements were taken in two winter month only, the dynamic ampacity is far beyond the static rating. During this period of time the relative dynamic ampacity rating was permanently higher than $150 \%$. This proves that during favourable weather conditions substantial additional ampacity is available. The rated current of the conductor bar is designed for summer ambient conditions which will be reached only occasionally during the year. Hence additional ampacity might be expected regularly. 
The results in figure 4 indicate that this is a highly loaded conductor bar since average values of the current load are in the range of $50 \%$ and peak values go up to $90 \%$. Dynamic ampacity rating will allow a higher utilisation of the conductor bar without exceeding the design temperature of $65^{\circ} \mathrm{C}$.

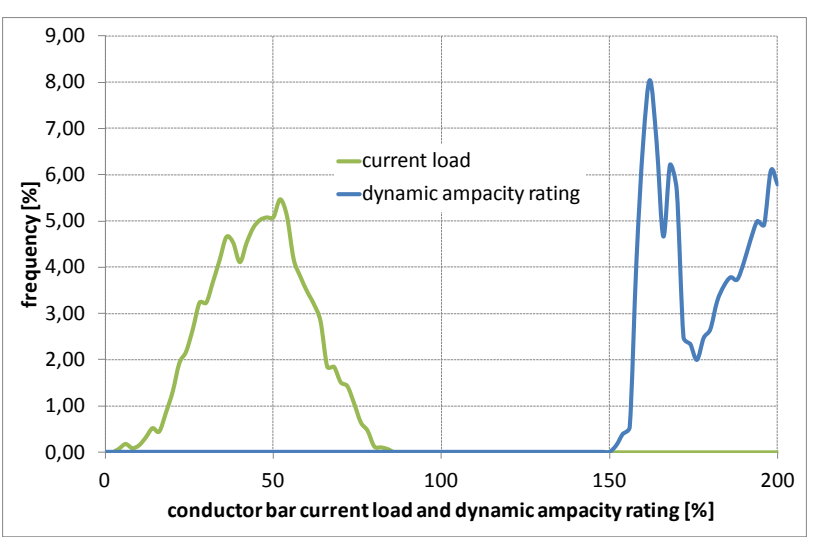

Figure 4: Current load of a conductor bar and corresponding dynamic ampacity rating

\section{RESTRICTIONS USING DYNAMIC RATING}

However, there are also restrictions using dynamic current ratings which need to be taken into account with regard to the stability of the grid going beyond the need of reactive power compensation [7]. In the distribution system as well as the transmission systems the influences on connected grids as well as the system stability depending on increasing phase angle differences need to be considered. Furthermore, the outage of a highly loaded line can cause transients on the lines remaining in operation. To avoid further outages defined boundary values of dynamic ampacity ratings should not be exceeded.

\section{CONCLUSION AND PERSPECTIVE}

A concept for dynamic ampacity rating of conductor bars has been set up. The necessary measurement equipment was installed in a switch bay of a substation. First evaluations of the data prove the validity of the physical models for conductor bars.

Measurement data will be recorded and evaluated at least for the period of one year. The integration into the control center is considered if future evaluations confirm the current results.

If using dynamic ampacity ratings in substations additional measures might have to be taken in order to use a higher transmission capacity. Where required other components have to be retrofitted for higher ampacities. In particular it is important to check and if necessary to replace connectors since higher currents can lead to accelerated aging.

\section{REFERENCES}

[1] DIN 43 670, Stromschienen aus Aluminium; Bemessung für Dauerstrom, 1975-12

[2] DIN 43 671, Stromschienen aus Kupfer; Bemessung für Dauerstrom, 1975-12

[3] IEEE 605-1998, Guide for Design of Substation RigidBus Structures, ISBN 0-7381-0327-6

[4] Cigré, Technical Brochure 207; The Thermal Behaviour of Overhead conductors, August 2002

[5] Dräger, H.-J.; Hussels, D.; Puffer, R.; Development and Implementation of a Monitoring-System to Increase the Capacity of Overhead Lines, Paper B2-101, Cigré Session 2008

[6] Schmale, M.; Puffer, R.; Dräger, H.-J.; Experience with a Dynamic Rating System to Increase the Ampacity of 380-kV Overhead Lines, Cigré Symposium, Bologna, 2011

[7] H. Kühn, F. Martin, M. Schmale, R. Puffer, W. Winter; Mehr Energie von Nord nach Süd, ew 3/2011 and 4/2011

[8] A. Webs; Dauerstrombelastbarkeit von nach DIN 48201 gefertigten Freileitungsseilen aus Kupfer, Aluminium und Aldrey, Elektrizitätswirtschaft $\mathrm{N}^{\mathrm{o}}$. 23, December 1963 